\title{
Model brain based learning (BBL) and whole brain teaching (WBT) in learning
}

\author{
Baiq Sri Handayani ${ }^{1}$, A.D. Corebima ${ }^{2}$ \\ ${ }^{1}$ Students of Postgraduate Malang State University \\ ${ }^{2}$ Lecturer of Biology Teaching Malang State University \\ Jalan Semarang 5, Malang 65145, INDONESIA \\ E-mail: ${ }^{1}$ sri_baidowi@yahoo.com \\ 2 duran.corebima.fmipa@um.ac.id
}

\begin{abstract}
The learning process is a process of change in behavior as a form of the result of learning. The learning model is a crucial component of the success of the learning process. The learning model is growing fastly, and each model has different characteristics. Teachers are required to be able to understand each model to teach the students optimally by matching the materials and the learning model. The best of the learning model is the model that based on the brain system in learning that are the model of Brain Based Learning (BBL) and the model of Whole Brain Teaching (WBT). The purposes of this article are to obtain information related to (1) the brain's natural learning system, (2) analyze the characteristics of the model BBL and WBT based on theory, brain sections that play a role associated with syntax, similarities, and differences, (3) explain the distinctive characteristics of both models in comparison to other models. The results of this study are: (1) the brain's natural learning system are: (a) the nerves in each hemisphere do not work independently, (b) doing more activities can connect more brain nerves, (c) the right hemisphere controls the left side motoric sensor of the body, and vice versa; (2) the characteristics of BBL and WBT are: (a) BBL is based on the brain's structure and function, while the model WBT is based on the instructional approach, neurolinguistic, and body language, (b) the parts of the brain that work in BBL are: cerebellum, cerebral cortex, frontal lobe, limbic system, and prefrontal cortex; whereas the parts that work WBT are: prefrontal cortex, visual cortex, motor cortex, limbic system, and amygdala, (c) the similarities between them are that they both rely on the brain's system and they both promote gesture in learning, whereas the differences are on the view of the purposes of gestures and the learning theory that they rely on. BBL relies on cognitive theory while WBT relies on social theory; (3) the typical attribute of them compared to other models are that in BBL there are classical music and gestures in the form of easy exercises, while on the WBT model there are fast instructions and movements as instructions or code of every spoken word.
\end{abstract}

\section{Introduction}

Learning is a process leading the learners carried out by a planned, implemented and systematically evaluated so that learners can achieve the learning objectives effectively and efficiently [1]. Teachers should understand that the demands of professionalism of teachers are not only able to develop material but also must be able to perform learning 
by engaging and meaningful. In order to achieve it, teachers need to understand how the brain works as a system of human intelligence in machine learning.

Understanding of the workings of the brain in learning can facilitate teachers in designing learning model. Currently, the development of science and technology has an impact on the development of models, strategies, and methods of learning. Brain-based learning is a new revolution in shaping the paradigm of cooperation some knowledge from various fields such as neuroscience, biology, and psychology [2]. The increasing number of learning activities undertaken by the students will make their synaptic nerves to be more connected and will make them more complex in that kind of thinking. The nervous system is the basis for a person's ability to understand, adapt and interact as well as receive, process, and then respond to information on the environment $[3,4]$.

Some models of learning associated with brain-based learning among them are Brain Based Learning (BBL) developed by Eric Jensen and models of Whole Brain Teaching (WBT) developed by Chris Biffle. Model BBL is a brain-based learning that is relevant based on the natural functions of the brain, where students can learn significantly with brains preparing students to store, process and retrieve information in a fun way $[5,6]$. $\mathrm{BBL}$ is a learning based on the idea that each part of the brain has specific functions that can be optimized in the learning process [7]. Model WBT is learning with instructional approaches derived from neurolinguistic picture based on the right and left brain function [3]. The brain system becomes the foundation in designing both learning models, but both models have different characteristics. This literature study will discuss: (1) the natural workings of the brain in learning, (2) the features of the two models in terms of the study of theory, syntax, and (3) the features of WBT and BBL compared to other learning models.

\section{Discussion}

\subsection{The Natural Workings of the Brain in Learning}

In the human brain, there is cerebellum consisting of four pairs of lobes, two left and right hemispheres of the brain and are connected by the corpus callosum $[9,10]$. The brain has more than one billion neurons; each neuron consists of hundreds of systems and subsystems that collaboratively process information. It is the task of the brain to plan, organize, predict a responsive motion by the situation at hand. About 100 billion neurons are composed of specialized cells that move into the information molecule and between neuronal networks that collaborate cognitive processing and motor sensory system. Molecular movement creates the perception of thoughts, decisions, and behavior. The right hemisphere is set to effectively and creatively interpret new challenges, and the left hemisphere to identify the challenges that are already known and then enable effective responses that developed previously [11].

In learning, more learning activities will connect more nerves in the brain. Brain learns new contents by (1) transmitting the information obtained from the senses to the thalamus for the early management, (2) simultaneously directing information to cortical for further processing, for example in the part of occipital lobe and temporal lobe, (3) 
directing information to subeorical areas, for example, the amygdala: amygdala respond immediately and recruit another brain area, (4) sending information to the hippocampus for a more stable evaluation and long-term storage, (5) and hippocampus organizes, distributes, connects the memory with the remaining area in the cortex for long-term storage [10]

Each hemisphere of the brain is not able to access information on their own, but they will cooperate in processing information. When information is received, they will respond because the right and left brain hemispheres are connected by grooves to have fibers called the corpus callosum [12]. The right hemisphere controls the left side of this sensory-motor activity of the body, while the right side activities are controlled by the left hemisphere. Eyes are more complex (visual field) for each eye to transfer information to both hemispheres of the brain [13].

The brain nerves will give response to any interaction that the body does with environment. The interaction may involve emotion such as happy or sad, cognitive, physical, self-reflection, and social relation. Everything that eyes see, ears hear, heart feels, brain thinks about, and body does, will give certain reaction to the brain. In learning, doing more activities may connect more nerves in the brain.

Teacher can create a fun learning system based on the brain system. Researches show that there are five systems that the brain brain develops: (1) emotional learning system: related to a comfortable classroom atmosphere; (2) social learning system: related to students' desire to be a part of a group, to be respected, to be noticed; (3) cognitive learning system: related to reading, writing activities, numeracy and all other aspects of academic development; (4) the physical learning system: the students are actively involved in learning relating to physical activities such as sports; (5) the reflective learning system: students' personal considerations related to the their learning [14].

\subsection{Analysis of Characteristics Brain Based Learning (BBL) and Whole Brain Teaching (WBT) Model}

\subsubsection{Theory of Brain Based Learning and Whole Brain Teaching Model.}

Brain Based Learning (BBL) is derived from the theory of cognitive neuroscience, the theory comes from studies of how the brain works function by neuroscience [8]. BBL is a learning model that is based on the structure and function of the brain $[5,6,16]$. One of the figures is a cognitive view of Piaget. According to Piaget, mental or cognitive processes includes schema, assimilation and accommodation, the organization and the equilibrium [17].

When teachers implement BBL, there are three strategies teachers: (1) creating a classroom atmosphere that is capable of stimulating the student's ability to think; (2) to bring students in an environment that are pleasant enough; (3) create an atmosphere of active and meaningful for students [16]. Based on this theory, students should be provided a learning environment that is safe and free from threats. Also, students learn 
the meaning and content of the brain Preparing students to store, process and retrieve information in a fun way $[6,17]$.

WBT is a method of learning by recognizing the principle of children's learning which consists of three parts: visual, verbal and body / kinesthetic. Furthermore, Biffle [8] explains that WBT is learning with instructional approaches derived from neurolinguistic picture based on the function of the left and right brain. WBT learning characterized by the ability of teachers to create innovative, and creative learning, so as to create a conducive and fun learning. To attract the attention of students the teacher can use voice with a distinctive intonation when presenting the subject matter or style with a gesture of its own when giving examples of specific behaviors [19]. Simple tasks and simple responses are the characteristics of WBT learning model than make the learning to be more interactive. Thus, this learning model can be applied to almost any lesson.

\subsubsection{Brain sections that play a role associated with Syntax BBL and WBT Model.}

Based on the brain-based principles of learning, the implementations of BBL in learning are as follows:

Table 1. Syntax of BBL learning model [10]

\begin{tabular}{|c|c|}
\hline $\begin{array}{l}\text { Learning } \\
\text { Syntax }\end{array}$ & Teachers' Activity \\
\hline Pre-Exposure & $\begin{array}{l}\text { Encouraging students to pay attention to brain nutrition and } \\
\text { encourage children to drink enough water } \\
\text { Stretching the muscles by doing right and left bending } \\
\text { Delivering the learning objectives }\end{array}$ \\
\hline Preparation & $\begin{array}{l}\text { Presenting issues or facts such as symptoms in everyday life } \\
\text { associated with the material being studied } \\
\text { Encouraging students to think about the connection between issues } \\
\text { or facts material to be learned with the subject matter before }\end{array}$ \\
\hline $\begin{array}{l}\text { initiation and } \\
\text { acquisitions }\end{array}$ & $\begin{array}{l}\text { Distributing Worksheet (LKS) } \\
\text { Preparing students to conduct activities such as observation both } \\
\text { inside and outside the classroom }\end{array}$ \\
\hline Elaboration & Assisting students in group discussions and class discussions \\
\hline $\begin{array}{l}\text { Incubation } \\
\text { and insert a } \\
\text { memory }\end{array}$ & $\begin{array}{l}\text { Playing classical music and asked students to stretch the muscles to } \\
\text { make students relax } \\
\text { Students write about what they have learned }\end{array}$ \\
\hline $\begin{array}{l}\text { Verification } \\
\text { and checking } \\
\text { conviction }\end{array}$ & Asking the students about what they learned today \\
\hline $\begin{array}{l}\text { Celebration } \\
\text { and } \\
\text { integration }\end{array}$ & $\begin{array}{l}\text { Giving awards to the students who are active either as individuals or } \\
\text { groups } \\
\text { Asking students to gave yells as to express their excitement of being } \\
\text { successful }\end{array}$ \\
\hline
\end{tabular}


If we study the syntax of BBL Model against the brain's natural learning system and its parts, the results are: (1) the pre-exposure stage belongs to physical learning system, in which the cerebellum controls body gesture, balance, and coordination consciously; (2) the preparation stage; (3) the initiation and acquisition stage belongs to cognitive learning system, in which the cerebral cortex plays a role in the processes of thinking, speaking, planning, analysis, and creativity; (4) the elaboration stage belongs to social learning system, where the frontal lobe manages the social behavior; (5) the incubation and memory encoding stahe belongs to reflective learning system, where the limbic controls emotion and memory; (6) the verificatin and confidence check belongs to cognitive and reflective learning system; and (7) the celebration and integration stage belongs to emotional learning, where the limbic works as it senses any treath, sadness, and fear. Also, the prefrontal cortex works when it detects happiness and comfort.

The syntax of the WBT model adapted from Biffle [20] is as follows:

Table 2. Syntax of Whole Brain Teaching (WBT) Learning Model

\begin{tabular}{ll}
\hline Learning Syntax & \multicolumn{1}{c}{ Teacher's Activity } \\
\hline Class-Yes & $\begin{array}{l}\text { The teacher focuses the students on learning by saying } \\
\text { "class-class" with a particular intonation. Students respond } \\
\text { "Yes-yes" with the same intonation with the teacher. }\end{array}$ \\
\hline Five Classroom & The teacher organizes the classes to mention five WBT class \\
rulers & The teacher explains some of the material outlined in a few \\
\hline Teach-Oke & seconds for each of the important concepts by using \\
& movement, and then the teacher pronounce the word "Teach" \\
& by clapping, and the student explain it to their friends with \\
& movement. \\
\hline The & To motivate students, the teacher gives a picture of a smile \\
for each completed task and a picture sad sign for each & incomplete task \\
\hline Switch & $\begin{array}{l}\text { The teacher gives a chance to students to give explanation } \\
\text { about certain tricky materials to other students by saying } \\
\text { "switch" first. }\end{array}$ \\
\hline Mirror & $\begin{array}{l}\text { The teacher gives the cue by saying "mirror," and the } \\
\text { students answer "mirror." Then, the teacher explains the } \\
\text { material with her body language and students should follow } \\
\text { what the teacher does. }\end{array}$ \\
\hline & $\begin{array}{l}\text { The teacher gives the cue to by saying "hands and eyes" and } \\
\text { students will respond similarly. After which, they fold their } \\
\text { hands on the table and listen carefully to the teacher's } \\
\text { explanation. }\end{array}$ \\
\hline
\end{tabular}

The relationship between each syntax and the parts of the brain are: (a) at the stage of Class-Yes and Hand and Eyes: the part of brain that responds is prefrontal cortex; (b) at 
the stage of Teach-Okey, Switch, there are five parts of the brain that react, namely: Visual cortex, motor cortex, Broca's area, Wernicke's area and the Limbic system; (c) at the stage of The Scoreboard, there will be limbic and amygdale that respond; (d) and at the stage of Mirror words, there will be visual cortex and motor cortex that respond [20].

\subsubsection{The Similarities and Differences between BBL and WBT Model.}

Looking at the theories and syntax of BBL and WBT, there are similarities and differences between them:

(a) The development of these two models is based on the system of the brain, but the difference is on the perspective of the way the brain processes information. BBL claims that learning should be adapted to the way the brain processes information that is receiving, storing, and retrieving information in a fun way [6], while the WBT claims that the way of learning which allows students to recall information is by activating every parts of the brain through coding and repetition.

(b) Both of them consider that movement is a crucial element in learning. The difference lies in the view of the purposes of movement. Movement on BBL aims to stretch the muscles so that blood circulates well to the brain during learning. On the other hand, movement on WBT aims to clarify the utterances, so that it is necessary to match the utterances with the body language and to code crucial information appropriately.

(c) Learning theory is the background of both models. Cognitivism which focuses on behavior, knowledge, intelligence, critical thinking, and learning as a result of mental process becomes the basis of BBL. Sensor memory interprets the stimulus at hand as an information. It will ignore the uninteresting information and transfer interesting information to short-term memory [21]. On the other hand, social learning theory of Albert Bandura becomes the basis of WBT. The learning activities in the model require students and teachers to do repetition of utterance and movement. According to Bandura most, humans learn by selectively observe and remember the behavior of others (model), the observation is later strengthened by linking new experiences with previous experience or repeating [22]

\subsection{The Characteristics of BBL and WBT Compared to other Learning Models}

BBL and WBT model are learning models have some unique features. The uniqueness of BBL is in the stages of incubation and inserting a memory, in which students listen to a classical music so that they will be comfortable. The research by Susanti and Rohmah [23] shows that classical music can reduce students' anxiety in learning mathematics. Mozerat effect music can improve spatial skills and increase alpha waves that have an impact on learning ability positively [24]. Classical music of Mozart can also improve emotional intelligence of students. They became more relaxed, concentrated, more excited, and the classroom became more comfortable so that the students could manage their emotions better [2].

Meanwhile, the characteristics of WBT is in the presence of quick instructions, active expressions, and body languages that can attract students' attention. Movement is the specific behaviors that result from muscles contractions. In WBT, it is a form 
response to the stimulus in learning. Stimulus pattern will gain more strength when paired with a response [25]. Based on researches, physical activity in the form of movements in learning can stimulate the liver to produce glucose to remain stable, in which it can support memory functions [15].

When someone is not sure of the given spelling, they will rely on movement that depends of their thoughts. Ratey proposed three points to explain the correlation between motoric sensors: (a) gesture is essential to its existence in the brain, (b) the frontal lobes of the brain specialized in the organization of physical and mental activities higher because brain function relies on these movements, (c) gesture is crucial for every brain functions including memory, emotion, language, and learning. Although eye movement seems so simple, it is actually critical to the way students access the knowledge and cognition. So far, teachers often ignore the fact that vision has something to do with movement or gesture. The control of eyes is so complicated because they transfer information to both hemispheres. Gesture can help constructing students' mental ability and energy. It also integrates new information and experience in the nerve tissue of the brain [13].

\section{Conclusion}

Based on the description above, there are some conclusions related to BBL and WBT in learning:

(1) The brain's natural learning system are: (a) the nerves in each hemisphere do not work independently, (b) doing more activities can connect more brain nerves, (c) the right hemisphere controls the left side motoric sensor of the body, and vice versa.

(2) The characteristics of BBL and WBT are: (a) BBL is based on the brain's structure and function, while the model WBT is based on the instructional approach, neurolinguistic, and body language, (b) the parts of the brain that work in BBL are: cerebellum, cerebral cortex, frontal lobe, limbic system, and prefrontal cortex; whereas the parts that work WBT are: prefrontal cortex, visual cortex, motor cortex, limbic system, and amygdala, (c) the similarities between them are that they both rely on the brain's system and they both promote gesture in learning, whereas the differences are on the view of the purposes of gestures and the learning theory that they rely on. BBL relies on cognitive theory while WBT relies on social theory.

(3) the typical attribute of them compared to other models are that in BBL there are classical music and gestures in the form of easy exercises, and while on the WBT model there are fast instructions and movements as instructions or code of every spoken word.

\section{REFERENCES}

[1] Depdiknas PK. Kurikulum tingkat satuan pendidikan (KTSP). Jakarta: Departement Pendidikan Nasional. 2006.

[2] Kurniawati LD, Ghozali I, Wartiningsih A. Effect of WA Mozart Classical Music Works Against Emotional Intelligence Class 5 SDN 06. J. Education and Learning. 2014:3(8).

[3] Lee LT, Hung JC. Effect of teaching using whole brain instruction on accounting 
learning. International. J. Distance Education Technologies (IJDET). 2009 Jul $1: 7(3): 63-84$.

[4] Strembeg K. J. \& Strembeg, K. 2012. Cognitive Psychology Sixh Edition. USA: California State University.

[5] Rangrej, Teaching Metodes Brain Based Learning. J. Electronik International Interdisciplinary Research (EIIRJ). 2012. 1(2): 94-100

[6] Malik MA, Hussain S, Iqbal Z, Rauf M. Effectiveness of Brain-Based Learning Theory on Secondary Level Students of Urban Areas. J. Managerial Sciences. 2012 Jan 1: 6(1).

[7] Siercks AM. Undestanding an Achieving Brain Based Instruction in the Elementary Classroom: A Qualitative Study of Strategies Used By Teachers (Doctoral dissertation, University of Central Florida Orlando, Florida).

[8] Biffle C. Whole Brain Teaching [serial on line]. http://www.wholebrainteaching.com . Accessed on 10 August 2013

[9] Akyurek E, Afacan O. Effects of Brain-Based Learning Approach on Students' Motivation and Attitudes Levels in Science Class. Online Submission. 2013 Apr: 3(1):104-19.

[10] Jensen, E. 2011. Brain Based Learning Paradigm of Teaching. Jakarta: Indeks

[11] Sylwester, R. 2012. Understanding the Development and Workings of a Child's Brain. Jakarta: PT Indeks.

[12] Kushartanti W. Optimizing Brain in Civilized Education System. Speeches Dies Natalis. 2004.

[13] Al Ghraibeh AM, Al-Zahrani AA. Learning and Thinking Styles Based on Whole Brain Theory in Relation to Sensory-Motor Integration. Research in Neuroscience.2013: 2(1):1-0.

[14] Given, B.K. 2007. Brain Based Teaching. Bandung: Kaifa.

[15] Jensen E. Brain-based Learning: A Reality Check. Educational Leadership. 2000: 57(7):76-80.

[16] Solapur, A. Teaching Methods Brain Based Learning. J. Electronic International Interdisciplinary Reasearch (EIIRJ).2012: 1 (2)

[17] Santrock, J.W. 2011. Educational Psychology, Second Edition. Jakarta: Kencana.

[18] Sapa'at. Brain Based Learning.(online), (http://matematika.upi.edu/index.php/brain-based-learning). Accessed on March 15th, 2014

[19] Suprijono, A. Cooperative Learning. Yogyakarta: Pustaka Belajar. 2010

[20] Biffle C. Whole Brain Teaching For Challenging Kids (and the rest of your class, too!). Whole Brain Teaching LLC; 2013.

[21] Subanji. Creative and Innovative Learning Mathematics. Malang: UM Press. 2011.

[22] Trianto. Learning Model in Theory and Practice. Jakarta: Prestasi Pustaka Publisher. 2007 
[23] Susanti DW, Rohmah FA. The effectiveness of classical music in lowering anxiety mathematics in class XI. J. psychology Indonesia. 2012 Apr $25 ; 8(2): 129-42$.

[24] Harmon L, Pelosi G, Pickwick T, Troester K. The effects of different types of music on cognitive abilities. J. Undergraduate Psychological Research. 2008;3:41-6.

[25] Schunk, D.H., Pintrich P.R. \& Meece J.T., 2012. Motivation in Education: Theory Research and Application. Jakarta: PT Indeks. 